\title{
Architectonic influences of multimedia and their spatial significance
}

\author{
Anne James \\ Department of Architecture and Design \\ Kyoto Institute of Technology \\ 606-0951 Kyoto-shi, Sakyo-ku \\ Matsugasaki Hashikami-chou, Japan \\ annejames.07@gmail.com
}

\author{
Dai Nagasaka \\ Department of Architecture and Design \\ Kyoto Institute of Technology \\ 606-0951 Kyoto-shi, Sakyo-ku \\ Matsugasaki Hashikami-chou, Japan \\ nagasaka@kit.ac.jp
}

\begin{abstract}
The prevalence of multimedia technology has influenced modern society in many ways. Technological and economic feasibility have enabled the application of multimedia to physical spaces, where media such as audio, visual and interactive content take on spatial significance.(McCollough 2005, pp. 154-165) This has spurred multidisciplinary ventures in architecture that explore the architectonic potential of multimedia. Particularly relevant, are the progressive spatial applications of multimedia evident in multimedia installation artworks and interactive spaces. Through a case study analysis of 25 works of multimedia installation art and interactive spaces, this paper seeks to understand the manner that multimedia influences an architectural space and determine the significance of such influences in an architectural context. Each work was examined using a systems theory (Heylighen 1992) approach, referencing the form of media implemented and its effect on the correlating space. 'Transformation', 'interaction' and 'temporality' were proposed as three relevant forms of multimedia influence. The proposed influences were assessed with respect to tectonics, topos and typos (Frampton 1995, p.2) to establish a matrix of effects indicating the spatial significance of the proposed influences relevant to an architectural context and sets up a theoretical basis to validate the viability of multimedia for architectural design.
\end{abstract}

Multimedia installation art. Interactive spaces. Architecture. Transformation. Interactivity. Temporality.

\section{INTRODUCTION}

Multimedia technology has become an indispensable part of society. It is evident in the computers, telecommunications devices, information devices and gaming systems that so many people use today to access and share information. To address applications in habitable, physical environments, multimedia technology has advanced beyond the confines of computing devices and began to integrate with the physical aspects of a space. Here, audio, visual and haptic media content, sometimes with interactive capabilities take on spatial significance. Spatial applications of multimedia have introduced modes of contemplating spatial function and structure that reflect not only how people experience and interact with a space, but also how a space can benefit people by sensing and interacting with them. (Bullivant, 2006, p. 617) With the integration of multimedia, spaces could become dynamic, responsive and interactive. Perceived limitations of time and space become more flexible and the gap between virtual and physical environments begins to bridge. (Bullivant, 2006, p. 9)
1.1 Relevance of multimedia Installation art and interactive spaces

Some of the most progressive examples of multimedia used in spatial applications can be found in multimedia installation artworks (Coulter-Smith, 2006) and interactive spaces. Since these works are not necessarily shaped by the same level of pragmatics necessary in an architectural project, multimedia installation artworks and interactive spaces have the freedom to explore ideas that might be too costly or unconventional for an architects to experiment with. (McLuhan, 2003, p. 16-35) Artists and designers often integrate aspects of multimedia, interactive design and information technology with architecture in the creation of their installation works. While architecture typically involves static physical elements that compose a constructed form and define a resultant space, multimedia installations and interactive spaces can involve dynamic elements that respond to and interact with people, the surrounding environment and data inputs to define a resultant space. In addition to the experimental work these artists and designers create with multimedia, the site specific nature of the works 
and emphasis on the human experience of a space, make multimedia installation art and interactive spaces particularly relevant to architectural design.

\subsection{Area of research}

This body of research is situated within an integrated area of study that covers multimedia technology, interactive design and architectural design. The aim of this paper is to understand the manner that multimedia influences an architectural space and determine the significance of such influences in an architectural context. Through indicating the functional potential of multimedia in architectural design, the interdisciplinary knowledge base that is necessary for multimedia to be used to its full potential as an integral element in architectural design can be advanced.

To work towards this goal, a case study analysis of works of multimedia installation art and interactive spaces was conducted. Works to be analysed were limited to art installations and interactive spaces that use multimedia as a primary component. Further constraints limited selections to works that incorporate an architectural context as an integral part of the work or themselves take on an architectonic function in the space. Focus was placed on contemporary works that exhibit an innovative use of multimedia to augment a space.

\section{METHODS OF RESEARCH}

\subsection{Systems theory approach}

In conducting the case study analyses, a systems theory approach was used to investigate the interrelated elements that comprise any multimedia installation work. Analyses were conducted independent of artists' intentions in order to focus on the effects of the multimedia works on their correlating space. Each installation functions as a system consisting of the multimedia implemented, the correlating installation space and the people that experience and interact with the space.

The multimedia component functions as a system in itself. It is composed of an input that is processed through computation and a corresponding output that is usually in a content form intended for human sensory perception.

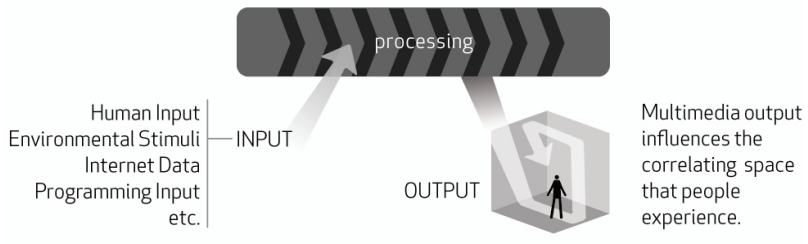

Figure 1: A typical multimedia installation system diagram
The reactions or responses of people in the space or changes in the environment that result from these outputs can function as new inputs to the multimedia system.

\subsection{Introduction to Frampton's three converging vectors}

To discern the influence of multimedia and its effect on a correlating space within an architectural context, this paper uses an architectural theory proposed by Kenneth Frampton. This theory states, 'the built invariably comes into existence out of the constantly evolving interplay of three converging vectors, the topos, the typos and the tectonic.' (Frampton, 1995, p. 2). Topos comes from the Greek word for place. It refers to the site, environment or context in which a building is situated. Typos literally means type and signifies the type of building space or purpose of a space. Tectonics refers to the physical construction of an architectural work or the built components that define a space.

Frampton's theory states the vectors of tectonics, topos and typos always converge to define any architectural space. As a result, these three vectors are effective referential points for analysing an existing space in order to derive and understand its architectural makeup. The spatial significance of multimedia influences could be assessed in the case studies by observing shifts that occur in the tectonics, topos or typos as a result of multimedia introduced.

\section{PROPOSED MULTIMEDIA INFLUENCES}

Based on their relevancy to an architectural context, the purposeful functionalities they afforded and the prevalence with which they were observed in the works analysed, this paper is proposing three forms of influence multimedia can have on a correlating space that will be referred to as transformation, interactivity and temporality. The following text will present transformation, interactivity, temporality and their spatial significance, supported by observations and analysis from key case study examples.

\subsection{Transformative influence}

The first form of influence proposed in this paper is transformation. It is generally defined as a dramatic change in form or appearance. Within the context of this paper, transformation refers to the observed ability of multimedia to influence a dramatic change in the perceived form, sense or function of a space.

\subsubsection{Case study 1: 'Audio Space'}

The 'Audio Space' installation is set in an interior space. Visitors wear special headsets equipped with stereo earphones, a microphone and location sensors. They are invited to walk around the room 
and input an audio recording of themselves talking or making vocal sounds at any point in the space. Each recording can then be heard again when standing in or near the position it was recorded. The various recordings associated with different points in the space function as an output that generates an audial structure that is perceptible as one moves around. Using stereo sound, the headset gives directional cues to where other recordings are located in relation to oneself.

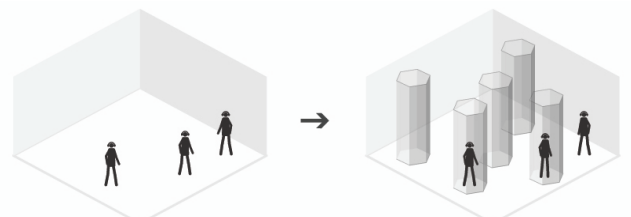

Figure 2: Audial structure created by people

\subsubsection{Using sound to create spatial structures}

Multimedia transforms a static tectonic structure by augmenting it with a structure composed of recorded sounds that can be navigated by hearing. While human hearing is attuned to the directional and spatial cues we can interpret from sounds we hear, it is often thought of as secondary to the visual and haptic senses for navigating and interpreting a space (Tuan, 2007, pp. 8-18). Here however, hearing is elevated to the primary mode of understanding a space.

The multimedia system used in this example presents a novel way of establishing spatial structure by correlating audial recordings with physical areas in the space. Another aspect of the audial structure is that it is created by people who visit the space. Thus, the structure responds to the input of people. The structure is cumulative, as it becomes more complex with new recordings added. People also contribute to the emotional character of the experienced structure as each person's recording has the potential to influence the experience of other people navigating through the audio space.

\subsubsection{Case study 2: 'The Grand Tour'}

The 'Grand Tour' installation is set in the exterior spaces of a dense urban environment. Framed reproductions of painting masterpieces were hung on exterior walls or facades. Accompanying each painting was a panel with a cell phone number that people could call to listen to a description of the work. In addition, the address was provided to a website where people could view maps with the location of other paintings and listen to or read descriptions of each work. On the website people could choose the paintings they were interested in and create their own itinerary through the city to see the physical works or select from a variety of themed itineraries.

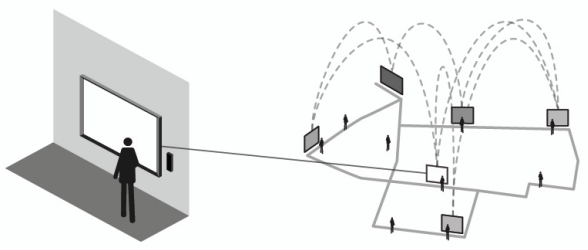

Figure 3: Spatial extent expanded with digital information

\subsubsection{The Significance of communications links in structuring spaces}

The reproductions accompanied by audial and visual information accessible by cell phone and internet communication links, compose a multimedia system that provides a flexible means of defining the extent of a space. Here, multimedia can significantly extend a given topology beyond a singular physical space by connecting distributed spaces linked by digital information that communicates their locations and the urban passages that physically interconnect them. People are able to decide the extent of the space for themselves based on the paintings they choose to see and the passages they use to get from one exhibit to the next.

Another aspect of this installation is a typological transformation afforded by the introduction of the multimedia system into public spaces distributed throughout the city. The everyday spaces where the reproductions are introduced are transformed into museum spaces for art. The reproductions hung on the street act as a visual cue to people and convey the artistic medium. Mobile and internet communications complete the experience by enabling an audio description of each painting and online maps that communicate the extent of the entire museum environment by locating all of the other paintings on display.

\subsection{Interactive Influence}

The second form of multimedia influence this paper is proposing is interactivity. For any interactive medium, there is an interface that is a point of interaction between a person and a multimedia system. As technology has advanced, possibilities for interfaces have expanded from a point of tangible interaction to spatial interactions where stimuli such as movements in a space can function as inputs to a system. (Hornecker, 2006) Within the context of this paper interaction refers to the observed ability of multimedia to provide responsive mechanisms that influence a physical environment.

\subsubsection{Case study 3: 'Funky Forest'}

'Funky Forest' is an installation set in an interior space. Projections on the walls depict a fantastical forest scene that interacts with children's actions in the space. Children use gestures to mimic the desired form and direction of a tree to grow and the projection on the wall responds with an animation of a tree sprouting to the size of their gestures. Each 
tree created prompts visuals of birds and insects creating the impression of a living forest ecosystem. Projections on the floor depict a river landscape that changes in response to the position, movements and gestures of children by altering the path of the river's flow. Computer generated sounds complete the playful forest ambient.

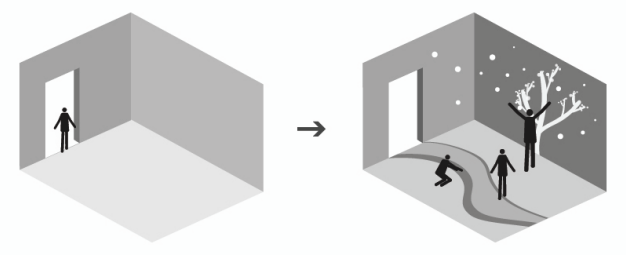

Figure 4: Interactive tectonics can respond to gestures

\subsubsection{Shaping an environment using human movement}

The interactive visual media projected on the walls and floor augment the perceived physical nature of tectonic elements to appear soft and malleable. Interactive, animated visuals alter the static physical state of the walls and floor to appear dynamic. The walls and floor in combination with the space they enclose are afforded new forms of function as an environmental interface where people can influence the visual nature of the environment with their movements and gestures. The actions of children in the space influence not only the perceived physical character of the space, but also the perceived function of the space. In this case, multimedia transforms a nondescript room into an interactive play space for children.

\subsubsection{Case study 4: 'Homographies'}

The 'Homographies' installation is set in a large interior space where a grid of fluorescent tube lights equipped with motion sensors is mounted on the ceiling. Each light is capable of rotating independently on a centre axis point. The motion sensors in the space respond to the presence and movements of people. The lights are programmed to rotate collectively to indicate the location of individuals in the space and their position relative to other individuals in the space. The visual pattern created by the rotated lights resembles the lines of magnetic forces and appear as lines of light that respond to the changing positions of people in the space.

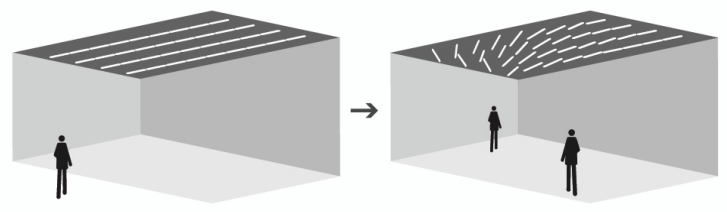

Figure 5: Spatial interactive elements creating socialising topos

\subsubsection{Interactive tectonics creating dynamic spatial contexts}

The responsive capability of the rotating light tubes gives augmented functionality to the space. Here, the ceiling functions as a dynamic motion sensing device. The light installation communicates the position of people in the space and also alludes to possible pathways that connect a person to other people in the space. This introduces a social-spatial element that could encourage social interactions between people.

The functional role of the ceiling is a peripheral one, as people often do not take notice of the space above their horizontal line of sight. Peripheral function is an important aspect of integrating multimedia with architectural design as the effective use of media in a physical environment does not have to dominate the experience of a space. In a peripheral role it can enable augmented functionalities for an environment without being distractive. (Redstrom, 2001, pp. 162-163)

\subsection{Temporality}

'The heart of one's sense of time is the sense of now', states Kevin Lynch (1976, p. 65), who theorised the significance of time in influencing one's sense of space. The third form of multimedia influence proposed is temporality. The standard definition of temporality is the state of existing within or having some relationship with time. The integration of multimedia into an architectural context introduces the systems, communications and interactions that require design in regard to both space and time. (Jones, 1992, p.,xxxii) Within the context of this paper, temporality refers to the observed ability of multimedia to afford the sense of nonlinear timelines for a space, where one's sense of time is altered or a juxtaposition to the expected timeline for a space is created.

\subsubsection{Case study 5: 'The Grand Tour'}

Referencing back to 'The Grand Tour' installation, there is also temporal dimension to this work as a result of the limited period of time it was exhibited. It is worth emphasising that all three forms of multimedia influence often occur simultaneously within one project. The temporary introduction of the installation's multimedia system into everyday urban environments affords these spaces alternative purposes. The multiple media function together to temporarily transform these spaces into museum spaces for art and possibly even impromptu gathering places for people viewing and discussing the art. The ease with which temporary changes in purpose can be achieved with multimedia gives architectural spaces increased flexibility to quickly and easily change typology to serve different needs. 

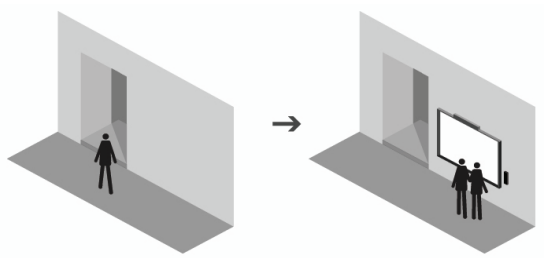

Figure 6: Using multimedia for temporary changes in purpose

\subsubsection{Using multimedia to temporarily repurpose a space}

Multimedia can be easily activated or deactivated and can to take on digital forms that can exist independent of a physical setting. As in 'The Grand Tour' installation, smaller projects can be temporarily implemented in multiple locations and linked by internet or mobile communication networks to other projects or spaces. Multimedia considered in this way, as another material in the construction of an architectural space, also has the potential to ease the burden of physical construction.

\subsubsection{Case study 6: 'Meta.L.Hyttan'}

The 'Meta.L.Hyttan' project was an experiment carried out by the Interactive Institute in Sweden to propose a living history installation for an old blast furnace hall in its past active state. People navigate the dimly lit hall with a flash light. Light sensors embedded in elements in the space respond to visitors' flashlight beams, triggering a multimedia display. A combination of visual, audial and physical media is activated to give temporal cues that simulate the once operational blast furnace hall. After a few minutes the multimedia display dims and the space returns to its current state. The implemented multiple media work in combination with physical elements in the space to influence one's sense of time.

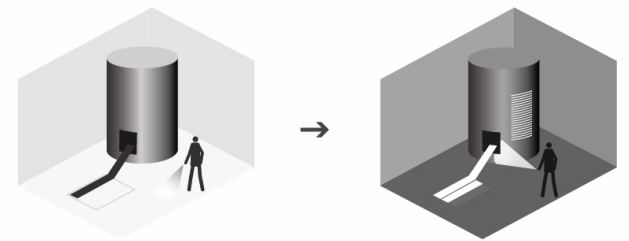

Figure 7: Temporal environment triggered by external stimuli

\subsubsection{The significance of temporal influences when constructing a sense of 'now'}

In this case, the temporal influence of multimedia functions to juxtapose the environmental ambient of two time periods in one space. With multimedia, physical elements are transformed to temporarily simulate a pre-existing space within the current state. Visual media is used to transform static physical elements to appear active and provide views into the inner workings of industrial machinery that are otherwise hidden. Sounds provide cues to the audial ambient of the working blast furnace hall.

Another aspect of temporality to consider is the sense of time a space imparts and its influence on people's experience of a place. With conventional building materials we construct a physical place understood as 'here', with the temporal influence of multimedia we can construct the sense of time understood as 'now'. Temporality introduces a new form of flexibility to consider in the design of an architectural space where time can be slowed down or sped up, people can experience another place in time or they can experience multiple time periods in juxtaposition.

\section{SYNTHESIS}

Findings from the case studies were synthesised to produce a unified theoretical model that establishes the effects of the proposed multimedia influences. To establish this model, Frampton's three vectors (tectonics, topos, typos) and the three proposed influences (transformation, interactivity, temporality) were integrated in a matrix, resulting in nine effects that successfully describe all observed cases. Reference Table 1. 
Table 1: Matrix of Multimedia Influences and their spatial significance with respect to Frampton's three vectors

\begin{tabular}{|l|l|l|l|}
\hline $\begin{array}{l}\text { Architectural } \\
\text { Vectors }\end{array}$ & \begin{tabular}{l}
\multicolumn{1}{|c|}{ Transformation: } \\
The observed ability of \\
multimedia to dramatically \\
change in the perceived form, \\
sense and function of a space.
\end{tabular} & $\begin{array}{l}\text { Interactivity: } \\
\text { The observed ability of multimedia } \\
\text { to provide responsive } \\
\text { mechanisms that influence a } \\
\text { physical environment. }\end{array}$ & $\begin{array}{l}\text { Temporality: } \\
\text { The observed ability of } \\
\text { multimedia to afford nonlinear } \\
\text { timelines for a space. }\end{array}$ \\
\hline Tectonics & $\begin{array}{l}\text { Transformative Tectonics: } \\
\text { Modulations in the form, sense } \\
\text { and function of tectonic element }\end{array}$ & $\begin{array}{l}\text { Interactive Tectonics: Tectonic } \\
\text { elements with the ability to sense, } \\
\text { react and interact }\end{array}$ & $\begin{array}{l}\text { Temporal Tectonics: Modulations } \\
\text { in tectonic form and function in } \\
\text { the context of time }\end{array}$ \\
\hline Topos & $\begin{array}{l}\text { Transformative Topology: } \\
\text { Modulations in topological cues } \\
\text { resulting in a changed sense of } \\
\text { place }\end{array}$ & $\begin{array}{l}\text { Interactive Topology: } \\
\text { Environments that can sense and } \\
\text { react to stimuli }\end{array}$ & $\begin{array}{l}\text { Temporal Topology: Modulations } \\
\text { in temporal cues that define a } \\
\text { space in the context of time }\end{array}$ \\
\hline Typos & $\begin{array}{l}\text { Transformative Typology: } \\
\text { Modulations in the function of a }\end{array}$ & $\begin{array}{l}\text { Interactive Typology: Spaces with } \\
\text { the ability to change purpose in } \\
\text { response to stimuli }\end{array}$ & $\begin{array}{l}\text { Temporal Typology: Modulations } \\
\text { in the sense timeline for a given } \\
\text { typology }\end{array}$ \\
\hline
\end{tabular}

\subsection{The effects of the transformative influence of} multimedia

\subsubsection{Transformative tectonics}

Transformative tectonics refers to the ability of multimedia to modulate the form, sense and or function of tectonic elements. In the 'Audio Space' installation the tectonic structure is augmented by an audial structure that transform the spatial structure of the room. This kind of alternative spatial structure can include not only physical media but also digital forms of media such as sound. In the case of the 'Audio Space' installation, transformative tectonics can also enable conventional tectonic elements augmented functionality, such as the 'Funky Forest' installation where the walls and floors are able to function as an interactive forest landscape.

\subsubsection{Transformative topology}

Transformative topology refers to the ability of multimedia to modulate topological cues that result in a changed sense of place. In the 'Audio Space' installation, sounds create a spatial structure that transforms the topology into an audial landscape experienced by audial perception. In reference to the 'The Grand Tour' installation, mobile phone and internet communications are used to construct an expanded topology that links places distributed throughout the city as one composite environment.

\subsubsection{Transformative typology}

Transformative typology refers to the ability of multimedia to alter the purpose of a space by altering its functional affordances. In the 'Audio Space' installation people can both create and experience the audial structure of the space. Multimedia makes it possible to transform a standard room into an interactive sound space.

\subsection{The effects of the interactive influence of multimedia}

\subsubsection{Interactive tectonics}

Interactive tectonics refers to the ability of multimedia to enable tectonic elements to sense, react and interact. In the 'Funky Forest' installation multimedia enables static tectonic elements to appear dynamic and interactive. As children are able to influence the visual character and function of the walls and floors with their movements and gestures.

\subsubsection{Interactive topology}

Interactive topology refers to responsive environments that can sense, react and interact. In the 'Homographies' installation the configuration of the rotating lights creates a socialising topos that senses the positions of people in the space and responds in real-time to suggest pathways that connect people in the space to each other.

\subsubsection{Interactive typology}

Interactive typology refers to the ability of a space to change purpose in response to stimuli. The multimedia system implemented in the 'Funky Forest' project creates an interactive environment that allows children's movements and gestures of the children to influence the perceived purpose of the space.

\subsection{The effects of the temporal influence of multimedia}

\subsubsection{Temporal tectonics}

Temporal tectonics refers to the ability of multimedia to modulate tectonic form and function in the context of time. The 'Meta.L.Hyttan' installation exhibits one aspect of temporal tectonics using projected visuals and sound to simulate machinery used in the blast furnace hall's original active state. In this example, multimedia gives a deeper understanding of an object by allowing people to contiguously experience its current state with its state in another point in time. 


\subsubsection{Temporal topology}

Temporal topology refers to the ability of multimedia to modulate temporal cues that change a space with respect to the context of time. The 'Meta.L.Hyttan' installation incorporates multimedia that influences the temporal perception of both tectonic elements and the ambient of the surrounding space. When activated, the quiet dimly lit space becomes illuminated and filled with the sounds and imagery of the blast furnace hall in its original active state. Altering the sense of time for an entire environment can give people a deeper experience of another place in time.

\subsubsection{Temporal typology}

Temporal typology refers to the ability of multimedia to shape the timeline of a space. Timeline refers to not only the sense of time for a space, but also duration. One example of 'temporal typology' is the ability of multimedia to temporarily change the purpose of a space. 'The Grand Tour' installation introduces a multimedia system that enables everyday urban spaces to be temporarily repurposed as museum spaces for art. In turn, the collection of networked spaces, temporarily function as an urban art museum.

\section{CONCLUSION}

This paper sought to understand the manner that multimedia influences an architectural space and determine the significance of such influences in an architectural context. The following conclusions were reached from case study analyses of 25 multimedia installation art works and interactive spaces.

Using Kenneth Frampton's theory as a basis (any work of architecture is understood to be defined by three converging vectors: tectonics, topos and typos), the influence of any given form of media on an architectural space can be determined by assessing the effect of the media with respect to the tectonics, topos and typos of the correlating architectural space. The case study analyses indicate that, with respect to the each of three vectors mentioned in Frampton's theory, 'transformation', 'interactivity' and 'temporality' are three key forms of multimedia influence in an architectural context. Integration of Frampton's three vectors with the mentioned three key forms of influence produces an array of nine effects that can be used as an unified theoretical model to identify and describe all observed cases of architectonic influence of multimedia.

In practice, such a model affirms the relevance and spatial significance of multimedia in an architectural context as it provides a method of gaining a structured insight into the relationship of media and architecture. Since a purposeful application of multimedia's capabilities as an architectural material implies an innovative approach to architectural design, these insights could be of equal interest to architects, artists and designers.

The findings from this study are intended to contribute to a theoretical framework supporting an integrated approach to multimedia and architecture and encourage new developments in architectural thinking as well.

\section{REFERENCES}

Note: all webpage addresses were successfully viewed on 1 April 2010.

Bullivant, L. (2006) Responsive Environments: Architecture, Art and Design. V\&A Publications, London.

Coulter-Smith, G. (2006), Installation Art. http://www.installationart.net/Chapter1/ntroduction/in troduction01.html

Frampton, K. (1995) Studies in Tectonic Culture: The Poetics of Construction in Nineteenth and Twentieth Century Architecture. The MIT Press, Cambridge.

Heylighen, F. and Joslyn, C. (1992) What is Systems Theory. http://pespmc1.vub.ac.be/systheor.html

Hornecker, E. and Buur, J. (2006) Getting a Grip on Tangible Interaction: A Framework on Physical Space and Social Interaction. In Proceedings of ACM CHI 2006 Conference on Human Factors in Computing Systems, Montreal.

Jones, J. C. (1992) Design Methods, second edition. John Wiley \& Sons., London.

Lynch, K. (1976) What Time is This Place?. MIT Press, Cambridge.

McCollough, M. (2005) Digital Ground: Architecture, Pervasive Computing and Environmental Knowing. MIT Press, Cambridge.

McLuhan, M. (2003) Understanding Media: The Extensions of Man. Ginko Press, Inc., Corte Madera.

Redstrom, J. (2001) Designing Everyday Computational Things. PhD Thesis, Göteburg University, Sweden.

Tuan, Y. (1977) Space and Place: The Perspective of Experience. University of Minnesota Press, Minneapolis. 


\section{APPENDIX OF WORKS REFERENCED IN THIS PAPER}

Note: all webpage addresses were successfully viewed on 1 April 2010.

Audio Space, Theo Watson.

http://muonics. net/v4/?id1=15\&xPos $=0$

Funky Forest, Theo Watson.

http://www.theowatson.com/site docs/work.php?id=41

Homographies, Rafael-Lozano Hemmer.

http://www.lozano-

hemmer.com/english/projects/homographies.htm

Meta.L.Hyttan Project, Smart Studio Interactive Institute. http://www.tii.se/avesta/

The Grand Tour, London National Gallery. http://www.nationalgallery.org.uk/download-thismonths-podcast/audio-tours/

\section{APPENDIX OF ALL OTHER ANALYSED WORKS}

Note: all webpage addresses were successfully viewed on 1 April 2010.

Aleph Reorganizing Vision, Adam Somlai-Fischer. http://www.vimeo.com/427989?pg=embed\&sec=427989

Audience, Chris O'Shea and rAndom International. http://www.randominternational.com/news/2008/10/23/audience-at-theroyal-opera-house.html

Beacon, Chris O'Shea.

http://www.chrisoshea.org/projects/beacon/\#video

Bridge, Michael Cross.

http://www.michaelcross.eu/bridge1.html

Contact, United Visual Artists.

http://www.uva.co.uk/archives/74

Daisies, Theo Watson.

http://www.theowatson.com/site docs/work.php?id=18
Displaced Emperors, Rafael Lozano-Hemmer. http://www.lozanohemmer.com/videos/displaced emperors linz.mov

Entramado, Pablo Valbuena. http://www.pablovalbuena.com/videos/pza letras vi deo.html

Ephemeral Forest, Workshop Levitas. http://www.workshoplevitas.org/

Frequency and Volume, Rafael Lozano-Hemmer. http://www.lozanohemmer.com/english/projects/frequency.htm

Four Stories, Ear Studio.

http://www.earstudio.com/projects/four stories.html

Gravicells, Seiko Mikami \& Sota Ichikawa.

http://g--r.com/

On Air, Christian Moeller.

http://www.christianmoeller.com/display.php?project id $=37$

Polygon Playground, White Void. http://www.polygon-playground.com/

Primal Source Project, Usman Haque. http://www.haque.co.uk/primalsource.php

Save Aveone, Graffiti Research Lab. http://graffitiresearchlab.com/?page id=85\#video

The Listening Post, Ben Rubin and Mark Hansen. http://www.earstudio.com/projects/listeningpost.html

The Weather Project, Olafur Eliasson. http://www.tate.org.uk/modern/exhibitions/eliasson/a bout.htm

Under Scan, by Rafael-Lozano Hemmer.

http://www.lozano-

hemmer.com/english/projects/underscan.htm

Weave Mirror, by Daniel Rozin.

http://www.bitforms.com/danielrozin.htm|\#id=22\&num=2 